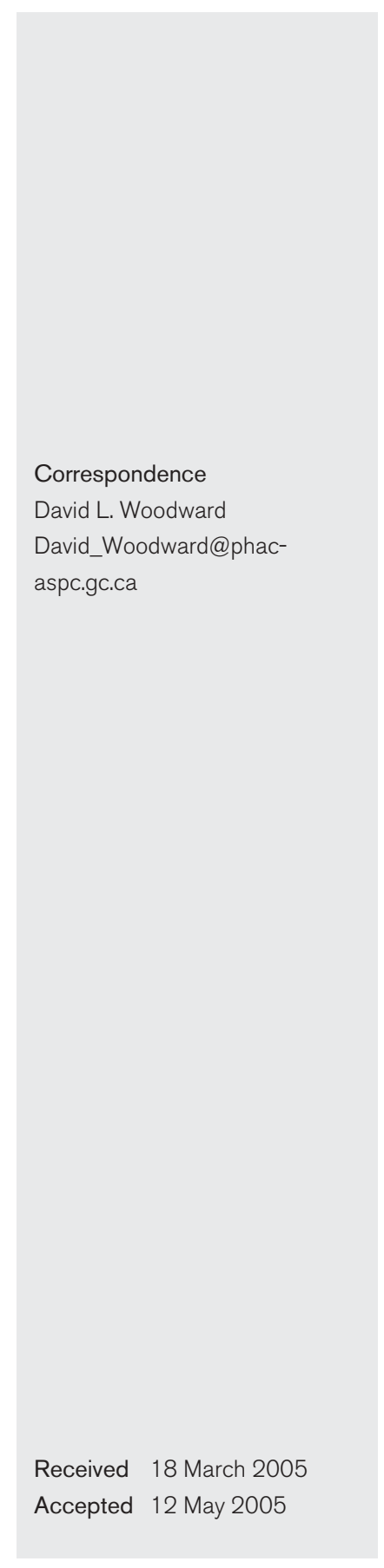

\title{
Identification and characterization of Shigella boydii 20 serovar nov., a new and emerging Shigella serotype
}

\author{
David L. Woodward, ${ }^{1}$ Clifford G. Clark, ${ }^{1}$ Richard A. Caldeira, ${ }^{2}$ Rafiq Ahmed, ${ }^{1}$ \\ Geoff Soule, ${ }^{1}$ Louis Bryden, ${ }^{1}$ Helen Tabor, ${ }^{1}$ Pasquale Melito, ${ }^{1}$ \\ Roger Foster, ${ }^{1}$ Julie Walsh, ${ }^{1}$ Lai-King Ng, ${ }^{1}$ Georgia B. Malcolm, ${ }^{3}$ \\ Nancy Strockbine, ${ }^{3}$ Frank G. Rodgers ${ }^{1,4}$ \\ and the Canadian Public Health Laboratory Network
}
${ }^{1}$ Bacteriology and Enteric Diseases Program, National Microbiology Laboratory, Public Health Agency of Canada, 1015 Arlington Street, Winnipeg, Manitoba, Canada R3E 3R2
${ }^{2}$ Bureau of Microbial Hazards, Health Products and Food Branch, Frederick G. Banting Building, Tunney's Pasture, Ottawa, Ontario, Canada K1A OL2
${ }^{3}$ Division of Bacterial Diseases, Center for Infectious Diseases, Centers for Disease Control and Prevention, 1600 Clifton Rd, Atlanta, GA 30333, USA

${ }^{4}$ Department of Microbiology, Rudman Hall, University of New Hampshire, Durham, NH 03824, USA

\begin{abstract}
Analysis of 163 putative Shigella isolates from Canada and the USA showed biochemical reactions consistent with Shigella species, although none of the isolates reacted with antiserum raised against any of the well-established or provisional Shigella serotypes. All these isolates, provisionally designated serotype $\mathrm{SH} 108$, were positive for the $\mathrm{ipaH}$ gene and the invasion-associated locus. All fermented mannitol, were serologically indistinguishable from each other and showed no reaction in antisera prepared against Escherichia coli serotypes O1 to O181. PCR-RFLP analysis of the genes involved in $\mathrm{O}$-antigen synthesis revealed a common pattern among these isolates that was distinct from recognized Shigella serotypes and E. coli. Between 1999 and 2003, isolates from across Canada were submitted to the National Laboratory for Enteric Pathogens for antibiotic susceptibility testing, phage typing and PFGE. These assays revealed heterogeneity among the members of this serotype. Antimicrobial susceptibility testing with seven antibiotics identified six profiles, with $90 \%$ $(45 / 50)$ of the isolates resistant to four or more antibiotics and $72 \%(36 / 50)$ resistant to five or more. All isolates were typable using a panel of 16 phages, with 11 different phage types (PTs) represented. The most common PTs found were PT 3 (64\%), PT 6 (10\%) and PT 16 (6\%). Analysis of $X$ bal-restricted genomic DNA revealed 16 highly related patterns that were not readily distinguishable from those obtained for some other Shigella serotypes. The World Health Organization Collaborating Center for Shigella has added serotype SH108 to the Shigella scheme as S. boydii serotype 20 (serovar nov.). Strain SH108 (isolate 99-4528) is the reference strain for this serotype.
\end{abstract}

\section{INTRODUCTION}

Infections with Shigella species cause approximately 600000 deaths worldwide annually. Two-thirds of all cases and most of the deaths occur among children under 10 years of age (Chin, 2000). Although more prevalent in developing countries, shigellosis is a worldwide problem. Transmission of the disease is primarily by person-to-person contact

Abbreviation: PT, phage type. through contaminated hands (Butler, 2000). Outbreaks typically occur under conditions involving close physical contact, such as those encountered in day-care centres, nursing homes, custodial institutions, cruise ships, aboriginal reservations and crowded refugee camps, with poor hygiene practices and contaminated food or water serving as the vehicle for infection (Brian et al., 1993; Chin, 2000; Edwards, 1999; Janda \& Abbott, 1998). The infectious dose of Shigella species is low, with $10-100$ bacteria sufficient to cause disease (International Commission on Microbiological 
Specifications for Foods, 1996; Trevejo et al., 1999; WHO Scientific Working Group, 1980).

Shigellosis is an acute infectious bacterial disease causing inflammatory enteritis in humans. Clinical manifestations of classical bacillary dysentery include fever, vomiting, abdominal pain, tenesmus (painful straining to pass stools) and stools containing blood and mucus resulting from invasion of the intestinal mucosa by the pathogen (Edwards, 1999; Janda \& Abbott, 1998; Keusch \& Bennish, 1998; Keusch, 1998). Despite this, however, many cases present with only a watery diarrhoea (Chin, 2000; Wathen-Grady et al., 1985). Shigellae are host-adapted to the human intestine (Janda \& Abbott, 1998). Illness is usually self-limited and lasts an average of 4-7 days, while the severity of illness and the casefatality rate are functions of the age and pre-existing nutritional state of the host, as well as of the serotype of bacteria causing disease (Chin, 2000).

The genus Shigella is divided into four subgroups that for medical purposes continue to be treated as species: subgroup A (Shigella dysenteriae), subgroup B (Shigella flexneri), subgroup C (Shigella boydii), and subgroup D (Shigella sonnei) (Bopp et al., 2003; Chin, 2000). S. flexneri, S. boydii and $S$. dysenteriae account for most cases of human disease in developing countries, whereas $S$. sonnei is more commonly isolated in developed countries (Janda \& Abbott, 1998). $S$. boydii is relatively rare in developed countries and is typically associated with individuals who have travelled to endemic areas.

S. boydii isolates can be difficult to distinguish from S. flexneri and enteroinvasive Escherichia coli. Isolates of this organism differ mainly in that they are typically agglutinated by $S$. boydii polyvalent group $\mathrm{C}$ antiserum and the corresponding monovalent factor antisera specific for serotypes 1-19. They are also differentiated by a recently described $r f b$ RFLP technique (Coimbra et al., 1999, 2001) that has proved to be an effective molecular method for rapid characterization of known Shigella O serotypes and for the detection of new Shigella O serotypes.
In 1999, the National Laboratory for Enteric Pathogens (NLEP) in Winnipeg, Canada, received eight lactose-nonfermenting, D-mannitol-fermenting Shigella isolates biochemically resembling $S$. flexneri. These isolates did not agglutinate in antisera specific for the group or type antigens of $S$. flexneri nor in antisera reactive with other recognized and provisional serotypes of Shigella. They also lacked the PCR-RFLP patterns characteristic of the molecular serotypes of the recognized Shigella serotypes (Coimbra et al., 1999). We have presented here laboratory and epidemiological findings on a collection of clinical isolates received in Canada and the USA that represent a newly emerging serotype of S. boydii designated $S$. boydii serotype 20 by the Centers for Disease Control and Prevention (CDC) in Atlanta.

\section{METHODS}

Strains. The S. boydii isolates that were characterized in this study were submitted, along with any associated information about the cases from which they were derived, by provincial Public Health Laboratories across Canada and state public health laboratories across the USA for confirmation of identification and serotyping results (Table 1; Demczuk et al., 2001; Kalluri et al., 2004). Isolates were routinely grown on nutrient agar and stored at $-80^{\circ} \mathrm{C}$ in either double-strength skimmed milk or trypticase soy broth containing $10 \%$ glycerol. Isolate $99-4528$, designated the $S$. boydii serotype 20 reference strain by the CDC, was used as a control for all tests. Strain 99-4528 has been submitted to the American Type Culture Collection (ATCC) and will be made available to others in the scientific community.

Biochemical tests and serotyping. S. boydii is typically non-motile, oxidase negative and catalase positive. Indole is variable, the methyl red test is positive, Voges-Proskauer and Simmons' citrate reactions are negative, and lysine decarboxylase, arginine dihydrolase and ornithine decarboxylase tests are negative. $\mathrm{H}_{2} \mathrm{~S}$ is not produced, urea is not hydrolysed and there is no growth in $\mathrm{KCN}$ broth. Carbohydrates are usually fermented and these include glucose (in the absence of gas production), D-mannitol, arabinose, trehalose and mannose (Holt et al., 1994). The biochemical reactions of the isolates were determined using the methods of Edwards and Ewing (Bopp et al., 2003; Ewing, 1986). Serological identification was performed by slide agglutination with polyvalent, somatic $(\mathrm{O})$ antigen grouping sera, followed by testing

Table 1. Distribution of isolates of $S$. boydii serotype 20 in Canadian provinces (1999-2003)

BC, British Columbia; AB, Alberta; MB, Manitoba; ON, Ontario; QC, Quebec; NB, New Brunswick; NS, Nova Scotia. ND, None detected.

\begin{tabular}{|ccccccccc|}
\hline Year & \multicolumn{7}{c|}{ No. of isolates } \\
\hline & BC & AB & MB & ON & QC & NB & NS & Total \\
\hline 1999 & 3 & 1 & ND & 2 & 2 & ND & ND & 8 \\
2000 & 3 & ND & ND & 3 & 5 & ND & ND & 11 \\
2001 & 9 & 5 & 2 & 6 & 2 & 1 & ND & 25 \\
2002 & 3 & 1 & ND & 1 & ND & ND & 1 & 6 \\
2003 & 4 & 1 & ND & ND & ND & ND & ND & 5 \\
Total & 22 & 8 & 2 & 12 & 9 & 1 & 1 & 55 \\
\hline
\end{tabular}


with monovalent antisera for specific serotype identification (Bopp et al., 2003; Ewing, 1986).

Phage typing. Bacteriophages were isolated from municipal raw sewage samples. Phage isolation, propagation, purification and typing were conducted using standard methods (Adams, 1959; Ahmed et al., 1987; Anderson \& Williams, 1956). A phage typing scheme was developed for S. boydii using 16 phages that were selected on the basis of distinct lytic reactions.

R-typing. Antimicrobial resistance patterns (R-types) were determined using BBL Sensi-Disc antimicrobial susceptibility discs (Becton Dickinson) according to procedures previously outlined by Bauer et al. (1966) and the NCCLS (2001). Antibiotics used in this study included ampicillin $(10 \mu \mathrm{g})$, chloramphenicol $(30 \mu \mathrm{g})$, ciprofloxacin $(10 \mu \mathrm{g})$, streptomycin $(10 \mu \mathrm{g})$, sulfadiazine $(0 \cdot 25 \mu \mathrm{g})$, tetracycline $(30 \mu \mathrm{g})$ and trimethoprim/sulfamethoxazole $(1 \cdot 25 / 23 \cdot 75 \mu \mathrm{g})$.

PCR tests. Isolates were tested for the presence of the ipa $H$ gene and for the invasion-associated locus diagnostic for Shigella and enteroinvasive E. coli as described by Sethabutr et al. (1993). PCR was used to demonstrate the presence or absence of stx genes and was performed according to the methods described by Paton \& Paton (1997).

PFGE. PFGE was done according to previously described protocols (CDC, 2000; Gautom, 1997). The S. sonnei F2353 standard strain was used as the size marker. Briefly, bacteria were grown overnight in brainheart infusion broth, washed in cell suspension buffer (100 mM Tris/ $\mathrm{HCl} \mathrm{pH} 8 \cdot 0,100 \mathrm{mM}$ EDTA) and suspended in the same buffer to give a density reading of approximately 0.50 in a Dade turbidity meter (Baxter Diagnostics). Proteinase K (Roche Molecular Biochemicals) was added to washed cells to a concentration of $1 \mathrm{mg} \mathrm{m}^{-1}$. Bacteria were then directly embedded in an equal volume of $1 \cdot 2 \%$ SeaKem Gold agarose (Mandel Scientific) and prepared using TE buffer $(10 \mathrm{mM} \mathrm{Tris/HCl} \mathrm{pH}$ $8 \cdot 0,1 \mathrm{mM}$ EDTA) containing $1 \%$ SDS. Solidified plugs were transferred to $1.5 \mathrm{ml}$ cell lysis buffer (50 mM Tris/ $\mathrm{HCl} \mathrm{pH} \mathrm{8.0,50} \mathrm{mM} \mathrm{EDTA,} 1 \%$ Sarkosyl, $0 \cdot 1 \mathrm{mg}$ proteinase $\mathrm{K} \mathrm{ml}^{-1}$ ) and incubated at $54{ }^{\circ} \mathrm{C}$ in a water bath with shaking at 200 r.p.m. for 2 h. Plugs were washed twice at $50^{\circ} \mathrm{C}$ with distilled water ( $18 \mathrm{M} \Omega$ quality) and three times for $15 \mathrm{~min}$ with TE. All washes were in water baths with shaking as outlined above. Plug slices were equilibrated in $100 \mu \mathrm{l}$ buffer $\mathrm{H}$ (Roche Molecular Biochem-

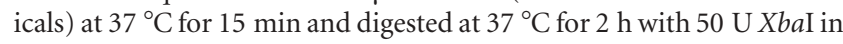
$200 \mu \mathrm{l}$ fresh buffer $\mathrm{H}$. After digestion, plugs were equilibrated in $0.5 \times$ TBE (0.89 M Tris/HCl, 0.89 M boric acid, 0.02 M disodium EDTA, pH 8.4; Roche Molecular Biochemicals) in $1 \%$ SeaKem Gold agarose at $14{ }^{\circ} \mathrm{C}$. Initial and final switch times were $2 \cdot 2$ and $54 \cdot 2 \mathrm{~s}$, respectively, and the total run time was $22 \mathrm{~h}$. Following electrophoresis, gels were stained with ethidium bromide $\left(0 \cdot 5 \mu \mathrm{g} \mathrm{ml}^{-1}\right)$ and imaged using the GelDoc 1000 system (Bio-Rad).

Molecular serotyping. Molecular serotyping was done according to previously published protocols with minor changes (Coimbra et al., $1999,2001)$. Bacteria were grown at $37^{\circ} \mathrm{C}$ for $14-18 \mathrm{~h}$ on nutrient agar containing $1.5 \% \mathrm{NaCl}$. Bacteria were embedded in low-melting-point agarose, lysed and washed according to the CDC PulseNet protocol for this organism (CDC, 2000) as outlined for PFGE (above). Each agarose plug was melted at $67^{\circ} \mathrm{C}$ for $15 \mathrm{~min}$ in $500 \mu \mathrm{l}$ TE buffer and $5 \mu$ l volumes were used for long PCR. The PCR primers 482 and 412, complementary to JUMPstart and gnd, were used with cycling conditions as previously described (Coimbra et al., 1999). Amplicons were separated by gel electrophoresis in $0.75 \%$ agarose gels using DNA Molecular Weight Marker III (Roche Diagnostics) to aid product size estimation. Between 8 and $20 \mu \mathrm{l}$ of product was digested for $2 \mathrm{~h}$ at $37^{\circ} \mathrm{C}$ with $10 \mathrm{U}$ MboII restriction enzyme (New England Biolabs), followed by denaturation of the enzyme for $10 \mathrm{~min}$ at $72{ }^{\circ} \mathrm{C}$. Digested samples were fractionated for $5 \mathrm{~h}$ at $140 \mathrm{~V}$ (constant voltage) in $2 \%$ agarose gels made with $50 \%$ typing-grade agarose and $50 \%$ Agarose 1000 (Invitrogen Life Technologies) using a $1 \mathrm{~kb}$ PlusDNA Ladder (Invitrogen Life Technologies) to allow gel normalization. RFLP patterns were normalized and analysed as outlined below using Bionumerics 2.1 software (Applied Maths). These patterns were compared with a library created in-house using all E. coli and Shigella serotype reference strains, as well as any additional isolates serotyped at the National Microbiology Laboratory (NML), Canada, using reference and molecular serotyping techniques.

Sequencing. Sequencing of the $16 \mathrm{~S}$ rRNA gene was performed as described by Edwards et al. (1989), using an ABI 3100 gene analyser (Applied Biosystems).

Analysis of data. Interpretation of the PFGE patterns was aided by the Bionumerics version 2.1 software. All associations obtained using this software package were checked visually by at least two laboratory staff familiar with PFGE interpretation. For the isolates analysed in this study, each unique pattern was given a separate designation. Similarity coefficients were obtained within Bionumerics by calculating Dice coefficients. Automated cluster analysis was performed within Bionumerics using the unweighted pair group method with arithmetic means (UPGMA) as a way of organizing banding patterns for visual comparison. Band position tolerances and optimization values of $1 \%$ were used throughout. All pattern matches were confirmed visually.

\section{RESULTS}

From 1999 to 2003, a total of 55 laboratory-confirmed cases of $S$. boydii serotype 20 infection were reported in seven Canadian provinces (Table 1). No seasonality was observed in the isolation or in the incidence of disease caused by these organisms. Infection with S. boydii serotype 20 was associated with recent travel to Cuba, Ethiopia, India, Guatemala and Mexico. S. boydii infections in Canada showed a steady increase between 1999 and 2000 (Table 1). Surveillance data indicated that in 1999 S. boydii serotype 20 represented $18 \%$ of laboratory-confirmed cases of $S$. boydii infection in Canada. By the year 2000, serotype 20 was the most frequent causative agent $(26 \%)$ of $S$. boydii infections in Canada.

\section{Phenotypic characterization of S. boydii serotype 20}

S. boydii reference strain 99-4528 appeared microscopically as Gram-negative straight rods. The biochemical reactions of serotype 20 strains are typical of those observed for other S. boydii serotypes (Table 2). Laboratory findings from reciprocal agglutination studies showed that the $\mathrm{O}$ antigen of strain 99-4528 was unique. This strain showed no agglutination in antisera prepared against the established and provisional serotypes of Shigella or in antisera specific for E. coli antigens $\mathrm{O} 1$ to O181. Of the various recognized Shigella serotypes and provisional serotypes, only the reference strain for $S$. boydii serotype 6 agglutinated in antiserum prepared against the $\mathrm{O}$ antigen of reference strain 99-4528 of S. boydii serotype 20. Adsorption of this antiserum with the reference strain to $S$. boydii serotype 6 was required to ensure the specificity of the S. boydii serotype 20 antiserum.

The $S$. boydii phage typing scheme was capable of subdividing isolates from well-characterized serotypes. There was a wide distribution of phage types (PTs) in reference strains 
Table 2. Biochemical reactions of $S$. boydii serotype 20 reference strain SH108 (99-4528)

TSI, Triple-sugar iron; V, variable.

\begin{tabular}{|lc|}
\hline Test & Reaction \\
\hline $\mathrm{H}_{2} \mathrm{~S}(\mathrm{TSI})$ & - \\
Urease & - \\
Indole & $\mathrm{V}$ \\
Methyl red $\left(37^{\circ} \mathrm{C}\right)$ & + \\
Voges-Proskauer $\left(37^{\circ} \mathrm{C}\right)$ & - \\
Simmons' citrate & - \\
Christensen's citrate & - \\
Sodium acetate & - \\
Sodium malonate & - \\
Mucate & - \\
KCN & - \\
Motility & - \\
Lysine decarboxylase & - \\
Arginine dihydrolase & - \\
Ornithine decarboxylase & - \\
Phenylalanine deaminase & - \\
$\beta$-Galactosidase $($ ONPG $)$ & - \\
Catalase & - \\
Oxidase & - \\
Glucose (acid) & - \\
Glucose (gas) & - \\
Lactose & - \\
Sucrose & - \\
Mannitol & - \\
Dulcitol & - \\
Salicin & - \\
Adonitol & - \\
Inositol & - \\
Sorbitol & - \\
Arabinose & - \\
Raffinose & - \\
Rhamnose & - \\
Maltose & - \\
Xylose & - \\
Trehalose & - \\
Cellobiose & - \\
Glycerol & - \\
Esculin & - \\
\hline
\end{tabular}

belonging to $S$. boydii serotypes 1-19. The $50 \mathrm{~S}$. boydii serotype 20 isolates were subdivided into 11 different PTs and none of the isolates tested was untypable. The most common PT, representing $64 \%$ of S. boydii 20 isolates, was PT 3 (Table 3).

Of the $50 \mathrm{~S}$. boydii serotype 20 isolates investigated using antimicrobial susceptibility testing, 45 (90\%) were resistant to more than four antibiotics (Table 4). Two isolates were resistant to six of the antibiotics tested and belonged to PT 5. The association between antibiotic R-type, PT, PFGE pattern
Table 3. PT distribution of $S$. boydii serotype 20 isolates in Canada (1999-2002)

\begin{tabular}{|lcc|}
\hline PT & No. of isolates & Percentage \\
\hline 1 & 1 & 2 \\
2 & 2 & 4 \\
3 & 32 & 64 \\
5 & 2 & 4 \\
6 & 5 & 10 \\
8 & 1 & 2 \\
10 & 1 & 2 \\
11 & 1 & 2 \\
14 & 1 & 2 \\
16 & 3 & 6 \\
17 & 1 & 2 \\
Total & 1 & 100 \\
\hline
\end{tabular}

and the country of travel for isolates from individuals with travel-associated disease is outlined in Table 5.

\section{Genotyping and subtyping}

All the isolates tested carried the ipaH gene and invasionassociated locus, but did not carry any detectable stx genes. Sequencing of the $16 \mathrm{~S}$ rRNA gene locus indicated that the S. boydii serotype 20 type strain was closely related to $S$. boydii ATCC 9207 (data not shown). Molecular serotyping through RFLP analysis of the locus responsible for O-antigen biosynthesis indicated that serotype 20 could be distinguished from serotypes $1-19$ (Fig. 1). PFGE analysis using XbaI was performed on all S. boydii serotype 20 isolates and individual reference isolates of $S$. boydii serotypes $1-19$. The resulting PFGE patterns were compared (Fig. 2) with XbaI PFGE patterns of a small number of $S$. sonnei and $S$. flexneri randomly selected from the PulseNet Canada Shigella PFGE database to determine whether PFGE would be a valuable tool for: (i) differentiating among serotypes; and (ii) differentiating among strains within serotype 20 .

The collection of 50 serotype 20 isolates was divided into 16 distinct $X b a I$ patterns that differed by only a few minor bands against a relatively conserved band arrangement. All serotype 20 isolates showed greater than $90 \%$ pattern similarity to each other, although there appeared to be sufficient pattern variability within even this small population to make PFGE using XbaI useful for confirmation of traceback investigations, disease surveillance and detection of case clusters that may be outbreaks. With the exception of serotypes 1,18 and 19 , serotype 20 isolates were less than $85 \%$ similar to the other $S$. boydii serotypes. PFGE patterns of the $S$. boydii serotype 20 isolates clustered more closely with PFGE fingerprints from some $S$. sonnei isolates than with isolates from other S. boydii serotypes, indicating that the clustering of PFGE patterns in this population does not reflect phylogenetic relationships. S. flexneri PFGE fingerprints also clustered among the S. boydii and S. sonnei patterns; the isolate showing the greatest PFGE pattern difference was 
Table 4. Antibiotic resistance profiles of S. boydii serotype 20 isolates with corresponding PTs

A, ampicillin; C, chloramphenicol; Ci, ciprofloxacin; S, streptomycin; Su, sulfadiazine; T, tetracycline; Tm, trimethoprim/sulfamethoxazole.

\begin{tabular}{|lcl|}
\hline Antibiogram & No. of isolates & \multicolumn{1}{c|}{ PTs represented } \\
\hline ACSSuTTm & 2 & PT 5 (2) \\
ASSuTTm & 34 & PT 1 (1), PT 2 (1), PT 3 (22), PT 6 (4), PT 8 (1), PT 11 (1), PT 14 (1), PT 16 (2), PT 17(1) \\
SsuTTm & 9 & PT 3 (9) \\
SsuTm & 3 & PT 2 (1), PT 3 (1), PT 10 (1) \\
ACST & 1 & PT 6 (1) \\
CT & 1 & PT 16 (1) \\
\hline
\end{tabular}

Table 5. Antibiotic resistance profiles, PTs and PGFE profiles of S. boydii serotype 20 isolates associated with travel

\begin{tabular}{|lccllcr|}
\hline Year & No. of cases & Province & Country of travel & R-type $\dagger$ & PT & PFGE pattern $\ddagger$ \\
\hline 2002 & 1 & BC & Guatemala & Sensitive & 3 & SBXAI.0037 \\
2002 & 1 & BC & Guatemala & Sensitive & 3 & SBXAI.0038 \\
2001 & 1 & AB & India & ST & 4 & SBXAI.0016 \\
2001 & 1 & AB & India & SsuTTm & 4 & SBXAI.0009 \\
2001 & 1 & MB & Ethiopia & ASSuTTm & 4 & SBXAI.0011 \\
2001 & 1 & QB & Mexico & SSuTTm & 4 & SBXAI.0017 \\
2002 & 1 & NS & Cuba & ASSuTTm & 3 & SBXAI.0038 \\
\hline
\end{tabular}

*For definitions, see Table 1 .

†For definitions, see Table 4.

$\ddagger$ SBXAI, S. boydii restricted with XbaI.

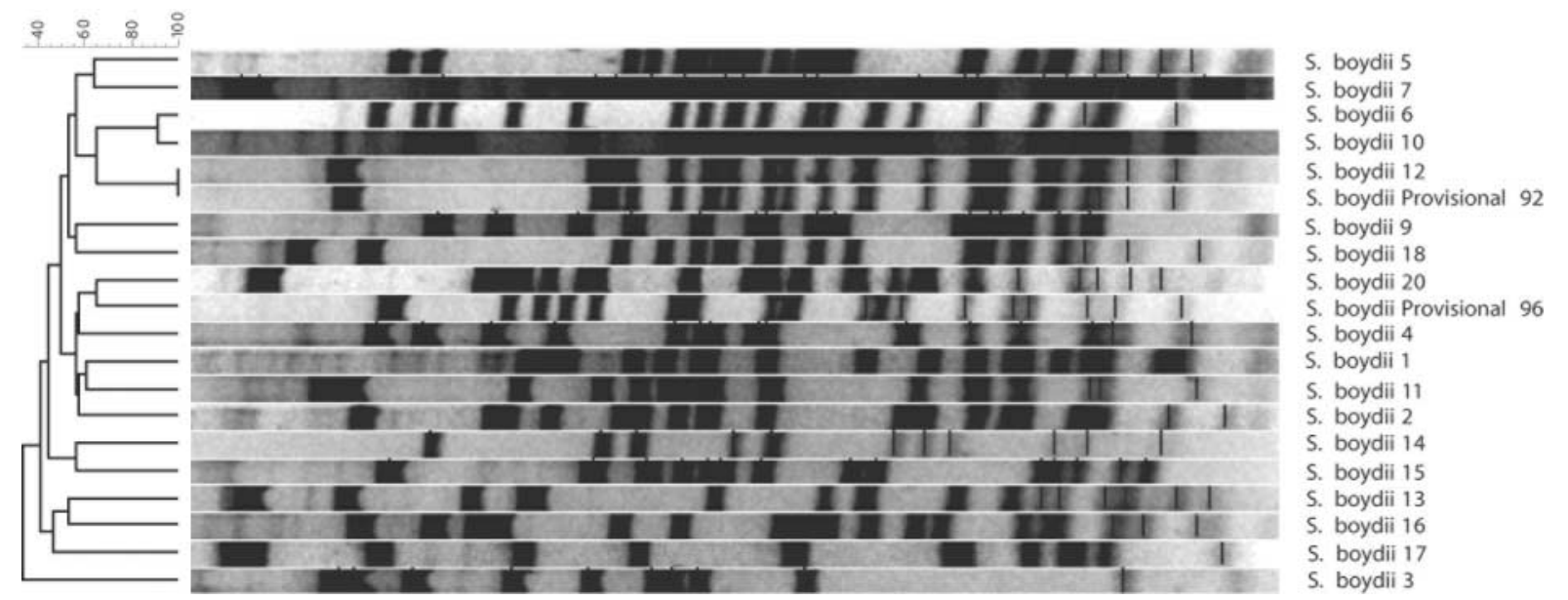

Fig. 1. O-antigen molecular serotyping patterns produced by PCR-RFLP.

S. boydii serotype 13 (Fig. 2). Because S. boydii isolates of serotypes other than 20 have either been rarely associated with human disease in Canada or have not been referred to our reference laboratory for more complete characterization, it was not possible to determine whether the PFGE patterns of the isolates used in this study were characteristic of each serotype as a whole.

\section{DISCUSSION}

Serological identification is a crucial step in the diagnosis of Shigella infections (Coimbra et al., 2001). In 1985, S. boydii consisted of a total of 18 serotypes after the addition of three new serotypes, S. boydii serotypes 16, 17 and 18 (Gross et al., 1980; Wathen-Grady et al., 1985). Serotype 19, represented 
PFGE-Xbal

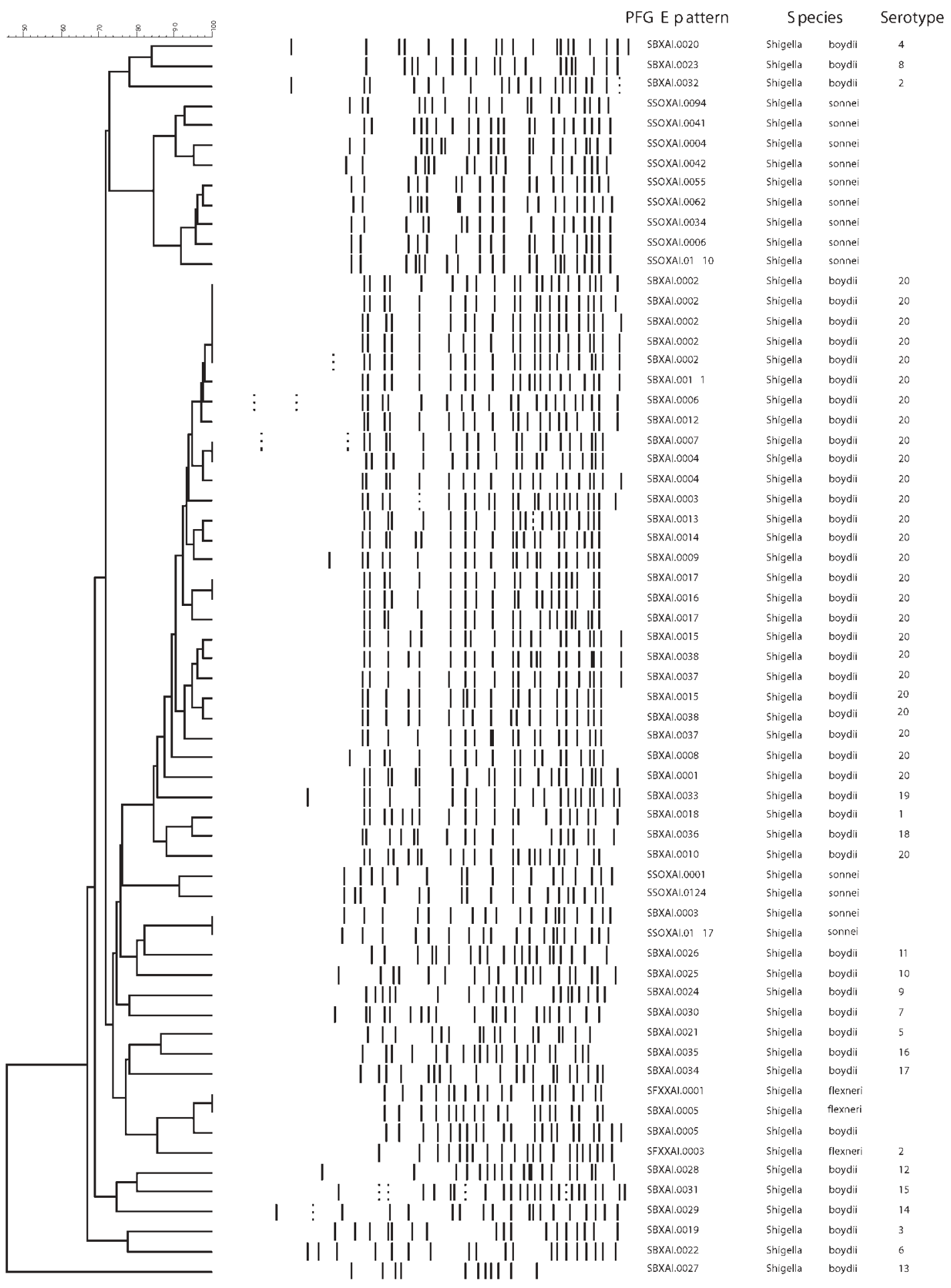

Fig. 2. Dendrogram showing the PFGE patterns of S. boydii serotype 20 isolates compared with other Shigella serotypes. The dendrogram was constructed with Bionumerics 2.1 software using the unweighted pair group method with arithmetic means (UPGMA) method. Thin lines were added by the program and show the location (peak of densitometry curve) of less-intense bands included in the analysis. 
by strain E16553 and first described in 1982, was recently added to the scheme (Gross et al., 1982).

S. boydii represents less than $1-2 \%$ of the total Shigella isolated, except in the Indian subcontinent (Keusch \& Bennish, 1998). In 1999, the NLEP in Canada identified what appeared to be a new emerging serotype of S. boydii. Epidemiological data identified seven cases that have been directly associated with travel to Cuba, Ethiopia, Guatemala, India and Mexico. While the other cases were not directly linked to travel outside Canada, the low prevalence of S. boydii endemic to this country suggests that they, too, might be travel associated. Cases of shigellosis associated with travel to Mexico and products exported from Mexico have been well documented (Crowe et al., 1999). Outbreaks of S. sonnei infection in the USA and Canada in 1998 were associated with parsley imported from Mexico (Crowe et al., 1999).

Between 2000 and 2003, the CDC received 108 isolates of S. boydii serotype 20 from 23 different states across the USA. An outbreak in California in 2001 was associated with 45 cases. At least 12 of the $45 \mathrm{~S}$. boydii serotype 20 cases associated with this outbreak were associated with travel to Mexico (Kalluri et al., 2004). As in Canada, the prevalence of cases associated with this serotype has increased dramatically in the USA. The epidemiology of this organism in the USA has recently been described by Kalluri et al. (2004).

The $S$. boydii phage typing scheme developed at the NML provided additional discrimination among $S$. boydii strains. PTs appeared to vary independently of serotype. Thus, while PT 3 was characteristic of a majority $(64 \%)$ of serotype 20 isolates, it was also found in the reference serotype 19 strain. Both PT and serotype could be used to obtain greater discrimination among strains.

Resistance to antimicrobial agents commonly used in the treatment of shigellosis is a continuing major problem in both developed and developing countries (Keusch \& Bennish, 1998). Shigella resistant to multiple antibiotics has appeared in all areas of the world, a phenomenon related to the widespread use of antimicrobial reagents (Chin, 2000). In this study high levels of resistance were observed, with 45 ( $90 \%$ ) of the 50 isolates of S. boydii serotype 20 tested being resistant to four or more of the seven antibiotics used (Table 4). It has been estimated that $93.5 \%$ of Shigella isolates associated with travel to developing nations are resistant to at least one antibiotic (Janda \& Abbott, 1998), suggesting that most strains expressing multi-drug resistance may be associated with travel.

It is difficult to assess whether the overall PFGE pattern similarity of the $S$. boydii serotype 20 isolates is characteristic of the serotype as a whole or whether it results from isolates representative of a widely circulating dominant clonal type present in Canada at the time. XbaI PFGE fingerprints of serotypes 1,18 and 19 were similar to those of serotype 20 strains. PFGE patterns from most serotypes exhibited similarities of $85 \%$ or less, suggesting that the larger population of S. boydii strains is less homogeneous than the serotype 20 strains studied to date. However, only a few strains have so far been included in the $S$. boydii database and further study is required to validate these observations. Little is known about the population structure of $S$. boydii as a whole or how organisms vary with their place of origin. However, it is clear that $X b a$ I PFGE pattern diversity within $S$. boydii is adequate for effective subtyping of strains.

The Shigella isolates described here, represented by the reference strain 99-4528, have been characterized using various phenotypic and genotypic epidemiological markers. Based on the identification procedures used, these strains have been designated S. boydii 20.

\section{ACKNOWLEDGEMENTS}

Canadian Public Health Laboratory Network members: Lewis Abbott (Prince Edward Island), Glenna Hardy (New Brunswick), Greg Horsman (Saskatchewan), Judy Isaac-Renton (British Columbia), Frances Jamieson (Ontario), Jean Joly (Quebec), Jutta K. Preiksaitis (Alberta), Sam Ratnam (Newfoundland), Paul van Caeseele (Manitoba).

We gratefully acknowledge the Provincial Laboratories of Public Health across Canada for the initial isolation and characterization of Shigella strains, for sharing data pertaining to cases from which isolates were obtained and for submitting Shigella strains to the Enteric Diseases Program for investigation.

\section{REFERENCES}

Adams, M. H. (1959). Bacteriophages. New York: Interscience.

Ahmed, R., Bopp, C., Borczyk, A. \& Kasatiya, S. (1987). Phage typing scheme for Escherichia coli O157: H7. J Infect Dis 155, 806-809.

Anderson, E. S. \& Williams, R. E. O. (1956). Bacteriophage typing of enteric pathogens and staphylococci and its use in epidemiology. J Clin Pathol 9, 94-127.

Bauer, A. W., Kirby, W. M. M., Sherris, J. C. \& Turck, M. (1966). Antibiotic testing by standardized single disk method. Am J Pathol 45, 493-496.

Bopp, C. A., Brenner, F. W., Fields, P. I., Wells, J. G. \& Strockbine, N. A. (2003). Escherichia, Shigella, and Salmonella. In Manual of Clinical Microbiology, 8th edn, pp. 645-671. Edited by P. R. Murray and others. Washington, DC: American Society for Microbiology.

Brian, J. M., Van, R., Townsend, I., Murray, B. E., Cleary, T. G. \& Pickering, L. K. (1993). Evaluation of the molecular epidemiology of an outbreak of multiple resistant Shigella sonnei in a day-care centre by using pulsed-field gel electrophoresis and plasmid DNA analysis. J Clin Microbiol 31, 2152-2156.

Butler, T. (2000). Shigellosis. In Textbook of Medicine, 21st edn, pp. 1685-1687. Edited by L. Goldman \& J. C. Bennett. Philadelphia, PA: W. B. Saunders.

CDC (2000). Standardized Molecular Subtyping of Foodborne Bacterial Pathogens by Pulsed-Field Gel Electrophoresis: Training Manual. Atlanta: Centers for Disease Control and Prevention. http://www.cdc.gov/ ncidod/eid/vol7no3/swaminathan.htm

Chin, J. (2000). Shigellosis. In Control of Communicable Disease Manual, pp. 451-454. Washington, DC: American Public Health Association.

Coimbra, R. S., Grimont, F. \& Grimont, P. A. D. (1999). Identification of Shigella serotypes by restriction of amplified O-antigen cluster. Res Microbiol 50, 543-553.

Coimbra, R. S., Lenormand, P., Grimont, F., Bouvet, P., Matsushita, S. 
\& Grimont, P. A. D. (2001). Molecular and phenotypic characterization of potentially new Shigella dysenteriae serotype. J Clin Microbiol 39, $618-621$

Crowe, L., Lau, W., McLeod, L. \& 29 other authors (1999). Outbreaks of Shigella sonnei infection associated with eating fresh parsley - United States and Canada, July-August 1998. Morbid Mortal Wkly Rep 48, 285-289.

Demczuk, W., Ahmed, R., Woodward, D., Clark, C. \& Rodgers, F. (2001). National Enteric Surveillance Program 2000: Annual Summary. Winnipeg, Manitoba, Canada: National Laboratory for Enteric Pathogens, National Microbiology Laboratory, Canadian Science Centre for Human and Animal Health.

Edwards, H. B. (1999). Salmonella and Shigella species. Clin Lab Med 19, 469-486.

Edwards, U., Rogall, T., Blocker, H., Emde, M. \& Bottger, E. C. (1989). Isolation and direct complete nucleotide determination of entire genes. Characterization of a gene coding for $16 \mathrm{~S}$ ribosomal RNA. Nucleic Acids Res 17, 7843-7853.

Ewing, W. H. (1986). Edwards and Ewing's identification of Enterobacteriaceae, 4th edn, pp. 135-172. New York: Elsevier.

Gautom, R. K. (1997). Rapid pulsed-field electrophoresis protocol for E. coli $\mathrm{O} 157: \mathrm{H} 7$ and other Gram-negative organisms in 1 day. J Clin Microbiol 35, 2977-2980.

Gross, R. J., Thomas, L. V. \& Rowe, B. B. (1980). New provisional serovar (E10163) of Shigella boydii. J Clin Microbiol 12, 167-169.

Gross, R. J., Thomas, L. V., Day, N. P., Cheasty, T. \& Rowe, B. (1982). New provisional serovar of Shigella boydii. J Clin Microbiol 16, 10001002.

Holt, J. G., Krieg, N. R., Sneath, P. H. A., Staley, J. T. \& Williams, S. T. (editors) (1994). Bergey's Manual of Determinative Bacteriology, 9th edn. Baltimore, MD: Williams \& Wilkins.

International Commission on Microbiological Specifications for
Foods (1996). Shigella. In Characteristics of Microbial Pathogens. Microorganisms in Foods 5, pp. 280-298. London: Blackie Academic \& Professional.

Janda, J. M. \& Abbott, S. L. (1998). The genus Shigella. In The Enterobacteria, pp. 66-79. Philadelphia, PA: Lippincott-Raven.

Kalluri, P., Cummings, K. C., Abbott, S. \& 10 other authors (2004). Epidemiologic features of a newly described serotype of Shigella boydii. Epidemiol Infect 132, 579-583.

Keusch, G. T. (1998). Shigella. In Infectious Diseases, 2nd edn, pp. 18041810. Edited by S. L. Gorbach, J. G. Bartlett \& N. R. Blacklow. Philadelphia, PA: W. B. Saunders.

Keusch, G. T. \& Bennish, L. M. (1998). Shigellosis. In Bacterial Infections of Humans: Epidemiology and Control, 3rd edn, pp. 631-656. Edited by A. S. Evans \& P. S. Brachman. New York: Plenum.

NCCLS (2001). Performance Standards for Antimicrobial Susceptibility Testing; 11th International Supplement. NCCLS publication M100-S11. Wayne, PA: National Committee for Clinical Laboratory Standards

Paton, A. W. \& J. C., Paton (1997). Detection and characterization of Shiga toxigenic Escherichia coli by using multiplex PCR assays for stx1, stx2, eaeA, enterohemorrhagic E. coli hlyA, $r f b_{0111}$, and $r f b_{0157}$. J Clin Microbiol 36, 598-602.

Sethabutr, O., Venkatesan, M., Murphy, G. S., Eampokalap, B., Hoge, C. W. \& Echeverria, P. (1993). Detection of Shigellae and enteroinvasive Escherichia coli by amplification of the invasion plasmid antigen H DNA sequence in patients with dysentery. J Infect Dis 167, 458-461.

Trevejo, R. T., Abbott, S. L., Wolfe, M. I., Meshulam, J., Yong, D. \& Flores, G. R. (1999). An untypeable Shigella flexneri strain associated with an outbreak in California. J Clin Microbiol 37, 2352-2353.

Wathen-Grady, H. G., Davis, B. R. \& Morris, G. K. (1985). Addition of three new serotypes of Shigella boydii to the Shigella schema. J Clin Microbiol 21, 129-132.

WHO Scientific Working Group (1980). Enteric infections due to Campylobacter, Yersinia, Salmonella and Shigella. Bull World Health Organ 58, 519-537. 